\title{
Applying Neural Network-Based Approach to Sickle Cell Disease-Related Pain Classification
}

\author{
Zacchaeus Omogbadegun, Israel Ogundele and Olufunke Oladipupo \\ Department of Computer and Information Sciences, Covenant University, Ota, Nigeria
}

\author{
Article history \\ Received: $19-06-2018$ \\ Revised: 08-01-2019 \\ Accepted: 27-06-2019 \\ Corresponding Author: \\ Zacchaeus Omogbadegun \\ Department of Computer and \\ Information Sciences, Covenant \\ University, Ota, Nigeria \\ Email: \\ zacchaeus.omogbadegun@covenantuniversity.edu.ng
}

\section{Introduction}

Siddique and Adeli (2013) stated that computational Intelligence (CI) promised to advance the healthcare sector and clinical practice of disease management in diagnosis, treatment, prevention, prescription and optimization of the fast delivery to patient with these diseases. Akinwonmi (2011) confirmed Artificial Neural Network (ANN)'s connection/strength could be determined by the activation function which could be either linear or non-linear. ANN's learning capabilities (supervised, unsupervised and reinforcement) are techniques used in learning. By adjusting the weight, the neural network adapts itself to learn and optimise to produce the desired output. Liu et al. (2006) affirmed ANN has been used in healthcare sector by applying the classification methods as ANNs identify the dataset features in order to accurately diagnose the nature of diseases, pains and sicknesses. Blood vessel occlusion accompanied by painful episodes and even death are evident in SCD (Macintyre et al., 2010; Jain and Gupta, 2016; and $\mathrm{Xu}$ et al., 2017). Symptomatic Sickle Cell Anaemia (SSCA)'s components are: (1) Mean Corpuscular Haemoglobin (MCH), (2) Red Blood Cells (RBCs) and (3) Hemoglobin (Hb or Hgb). Normal RBC range in Males is 4.7 to 6.1 million cells per micro liter (cells $/ \mathrm{mcl}$ ) and in females is 4.2 to 5.4 million cells $/ \mathrm{mcl}$. People suffering from SSCA have RBC in the range $2.37-3.73$ cells $/ \mathrm{mcl}$ with value variations as in Table 1 (Jain and Gupta, 2016).

SCD becomes one of the most common severe lifethreatening haematological and monogenic disorders affecting millions of people worldwide. SCD occurs in people of African, Arabic and Indian racial backgrounds with countries in Equatorial Africa bearing the greatest burden (Piel et al., 2013; Kristiansen, 2014). As shown in Table 2, worldwide, over 300,000 babies are born with SSCA yearly having sickle hemoglobin gene and this figure may increase to 400,000 by the year 2050 . 
Table 1: Normal and anaemic range of $\mathrm{RBC}, \mathrm{MCH}$ and $\mathrm{Hb}$ (Jain and Gupta, 2016)

\begin{tabular}{lll}
\hline Blood components & Normal range & Anaemic range \\
\hline RBC(cells/mcl) & $4.2-6.1$ & $2.37-3.73$ \\
$\mathrm{MCH}(\mathrm{pg})$ & $25.63-29.23$ & $26.52-32.16$ \\
$\mathrm{Hb}(\mathrm{g} / \mathrm{dl})$ & $25.63-29.23$ & $6.63-10.87$ \\
\hline
\end{tabular}

Table 2: Burden of sickle cell disease (Kristiansen, 2014)

\begin{tabular}{ll}
\hline Country & Sickle cell births/year \\
\hline Nigeria & 91,011 \\
Dem. Rep. Congo & 39,743 \\
Tanzania & 11,877 \\
Uganda & 10,877 \\
Angola & 9,017 \\
Cameroon & 7,172 \\
Zambia & 6,039 \\
Ghana & 5,815 \\
Guinea & 5,402 \\
Niger & 5,310 \\
Sub-Saharan Africa Total & 242,187 \\
Worldwide Total & 305,773 \\
\hline
\end{tabular}

The usual disorder in an individual is SCD. Rees et al. (2010; Akinsete and Osu, 2017) have reported that 43 million people have sickle-cell traits and 4.4 million people have SCDs. Akinsete and Osu (2017) also estimated that 40 million Nigerians are carriers of this disease with over 150,000 infants born with SSCA. This situation translates to Nigeria having the highest record of SCD, where infant's death of this carrier is estimated to be 100,000 in Nigeria representing eight percent of her mortality rate.

Case et al. (2018) submitted that SCD's management would social and cultural sensitivity of the practitioner's expert and experience due to the patient's challenging condition. Mechanisms behind SCD-related pain and the best way to treat same have not been well understood (Dampier et al., 2014). Vaso-Occlusive Crises (VOC) constitute SCD's painful episodes. Acute and chronic pains are mostly associated with adult patients, while acute pain is common in infants and children to classify the pain based on recent findings. Despite advances in the understanding and management of acute pain in other clinical settings, SCD's acute painful crisis management remained unsatisfactory (Telfer et al., 2014). It has been difficult for patients to receive high quality care outside of specialty centers following the lack of a strong evidence base to guide the management/treatment of SCD-associated acute pain episodes (Lanzkron and Carlton, 2015). According to Poku et al. (2018) and Ginter et al. (2018), most hospitals and healthcare practitioners are using the traditional manual approach for management of patients with SCD, which can be time consuming and stressful to both patients and practitioners. Lanig et al. (2018) affirmed the daily increase in SCD would require more sufficient resources, such as healthcare professionals and practitioners, which are said to be inadequate. Devi et al. (2013; Reader et al., 2017) reported ANN has been applied to SCsD for diagnosis, prediction and classification. However, this has not been applied for SCDs-related pain management.
Table 3: Optimization of the ANN in solid dosage form (Ibrić et al., 2012)

Training of the network

Data is presented to the network

Network computes an output

Network output is compared to desired output

Network weights are modified to reduce error

Usage of the network

Present new, unseen data to the network

Network computes an output based on its training

\section{Artificial Neural Network Optimization}

Jin et al. (2005) reported different researchers have compared various techniques such as Back-propagation, Simulated Annealing, ANN and Genetic Algorithm (GA) for optimizing processes in a network. While Simulated Annealing and GA have been proved to be global search techniques for optimization, Back-propagation algorithm is the mostly used for optimization techniques for training the neural network to find optimal solutions. While datasets are fed into the network through the input layer, the weight in the network is updated, by adjusting in an attempt to optimize the process and minimize the loss function, Sun et al. (2003) observed that best solutions are obtained in the area of the point which is more effective and consistent. In adjusting the weight, Agatonovic and Beresford (2000) had earlier stated that the interconnections of the nodes are strengthened while some are dropped (weakened) so that the neural network can output a better solution. Finally, the network training comes to halt when the best and optimal solution is obtained. Ibrić et al. (2012) opined that datasets' features could be classified into training and test datasets at a start of the training. Furthermore, the predictive uses test data while the training data is used to obtain optimal solution which changes the error, while the evaluation of the data is done by using both training and test data. The latter is done simultaneously. Table 3 shows the steps to follow in supervised training of network and usage.

\section{Sickle Cell Disease-Related Pain}

A reassessment of the diagnosis and consideration of alternative causes of an uncontrolled or unexpected pain (e.g., new surgical/medical diagnosis, neuropathic pain) would be expedient (Macintyre et al., 2010). Pain management in SCD is challenging due to both the frequent crisis being faced by the patient and the inability of the healthcare practitioner to quickly identify the pain as the RBC disorder constitutes the cause of the painful complication in SCD as ascertained by Case et al. (2017). Ballas (2005) had earlier classified pains in SCD as chronic pain, acute pain, neuropathic pain or mixed pain. These are unpredictable and can occur at any time. Chronic pain is the outcome of the frequent acute pain that has not been properly taken care of. The pain can be experienced between three months and more. Some of the symptoms are achy, frequent in nature and this happens in a pathophysiologic events. Acute pain can occur throughout 
the life of the SSCA patient. The pain can be so sudden leading to Vaso-Occlusion (VOC) crisis and can cause damage to the organ which can sometimes lead to death if not properly managed. Neuropathic pain occurs as a result of wound or dysfunction in the body and is associated with SCD which can be triggered by harmful or deadly things. SCD-related pain classification is associated with increased morbidity, mortality and high health care costs (Ballas, 2005; Dampier et al., 2017). Adopting a Proforma for Pain Assessment as given in Fig. 1 enhances SCD pain research efforts in epidemiology, pain mechanisms and clinical trials of pain management interventions that will ultimately improve clinical assessment and management (Howard and Telfer, 2015; Dampier et al., 2017).

Due to the challenges in identifying and treating the painful episodes of the SCD which occur from offspring and can continue throughout the lifespan of that patient, frequent pain of acute nature requires quality healthcare and attention by the practitioners. Acute Chest Crisis (ACS) monitoring with regular assessment of respiratory rate, oxygen saturation and daily examination of the chest constitutes an essential part of Acute Painful Crisis (APC) (Macintyre et al., 2010; Howard and Telfer, 2015; Case et al., 2017).

\section{The Sickling Phases}

Hemoglobin has a rope-like structure - the sickle which is a trait in SSCA. Molecules of the hemoglobin are put together to form fibres and then aggregated into twisted pairs. US_NIH (2014) affirmed SSCA-hemoglobin consists of four sickling phases: $\mathrm{HbS}, \mathrm{P}^{+}$chain, deoxy+bs and polymer while each of the hemoglobin molecules is called heme group. Abnormal sickle-shaped erythrocytes' rigidity to disrupt blood flow in small vessels arises from haemoglobin polymerisation. Figure 2 shows the sickling phases (Howard and Telfer, 2015; Afolabi et al., 2016).

\begin{tabular}{|lc|}
\hline Patients name: & Hosp\# \\
Sex M/F (circle) & DOB \\
\hline
\end{tabular}

Pain and Analgesia Assessment

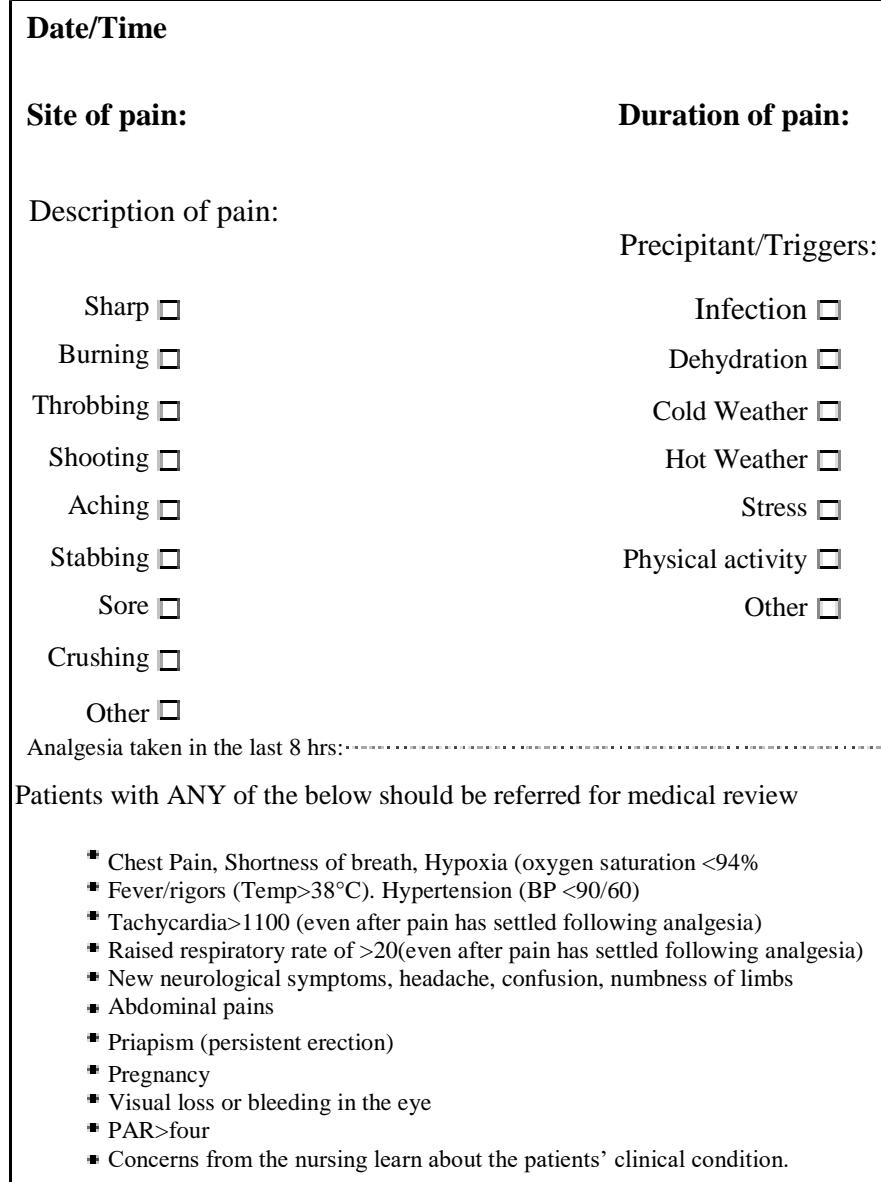

Fig. 1: Proforma for pain assessment (Howard and Telfer, 2015) 


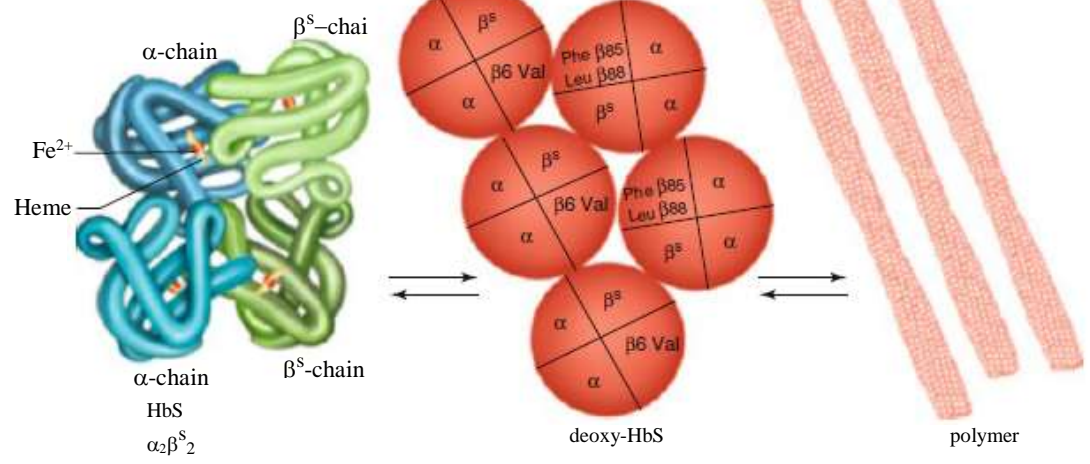

Fig. 2: Sickling Phases (Howard and Telfer, 2015)

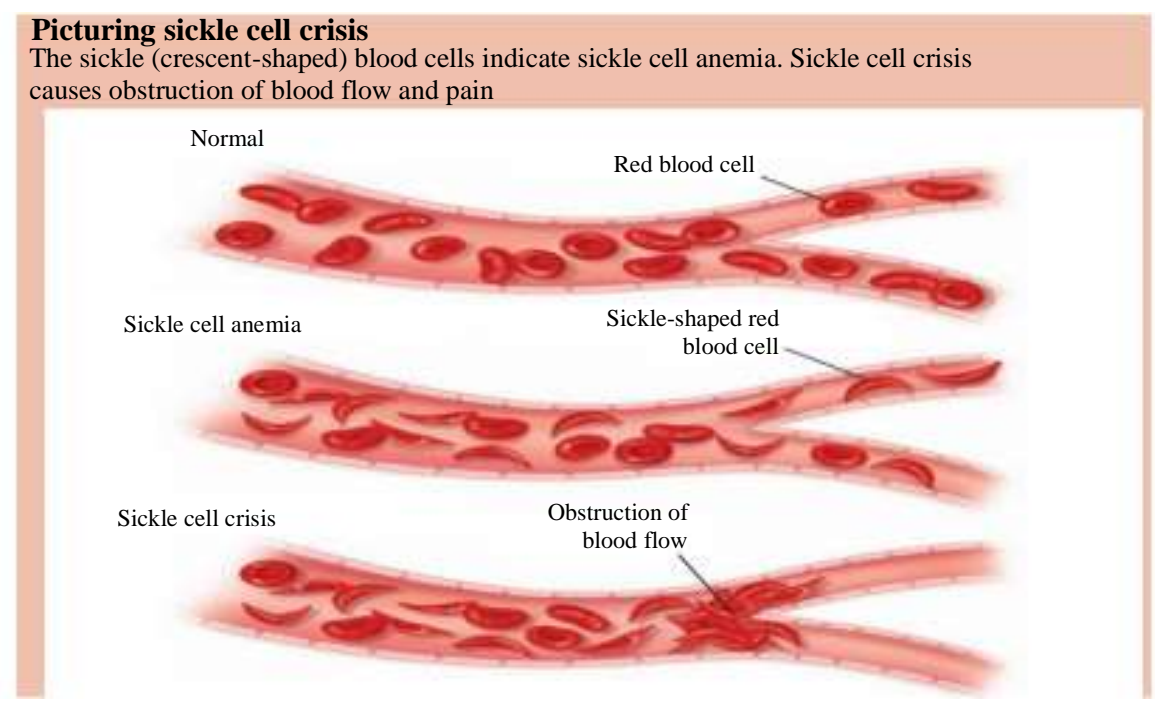

Fig. 3: Picturing sickle cell crisis (Creason, 2010)

The most prevalent SCD genotypes associated with the most severe clinical manifestations include homozygous hemoglobin SS (HbSS) and the compound heterozygous conditions hemoglobin S $\beta 0$-thalassemia (HbS $\beta 0$ thalassemia), hemoglobin $\mathrm{S} \beta+$-thalassemia ( $\mathrm{HbS} \beta+-$ thalassemia) and hemoglobin SC disease (HbSC). Distal tissue ischaemia and inflammation, with symptoms defining the acute painful sickle-cell crisis arises from vaso-occlusion (central to the pathophysiology SCD). The importance of chronic anaemia, haemolysis and vasculopathy has been established. Parenchymal injury and chronic organ damage, causing substantial morbidity and early mortality, result from repeated sickling and ongoing haemolyticanaemia. Consequences of sickling include destruction to the membrane and cytoskeleton, removal in the RBC, red cell dehydration and impaired anti-oxidant mechanisms. Figure 3 shows the sickle cell crisis which causes obstruction of blood flow and pain.

Excess morbidity and mortality, particularly from respiratory suppression and excessive sedation, could be experienced from inappropriate dosing of potentially toxic opioid drugs (Howard and Telfer,
2015). Frequent monitoring of vital observations including respiratory rate and sedation score is obligatory, using Pain Assessment Scale of Fig. 4 (Howard and Telfer, 2015; Dampier et al., 2017).

\section{Vaso-Occlusive Crisis}

'Vaso-Occlusive Crises' (VOC), arises from intermittent and recurrent acute pain episodes of SCD, (Lanzkron et al., 2010). Furthermore, most adults and infants experienced these painful episodes (being the most common with people having SSCA). VOC occurs when there is coagulation of the RBC and this can lead to severe injuries or damage to the organ of the body which is the most common in the complication. The SSCA's severe complication is responsible for Emergency Department (ED) and healthcare sector for SCD patient to receive quick treatment with high quality and outmost care to save life. Complication occurrences can lead to VOC. Every SCD patient experiences this VOC during his/her life span and if the person is not being taken care of during the time of the crisis, it might lead to death. 


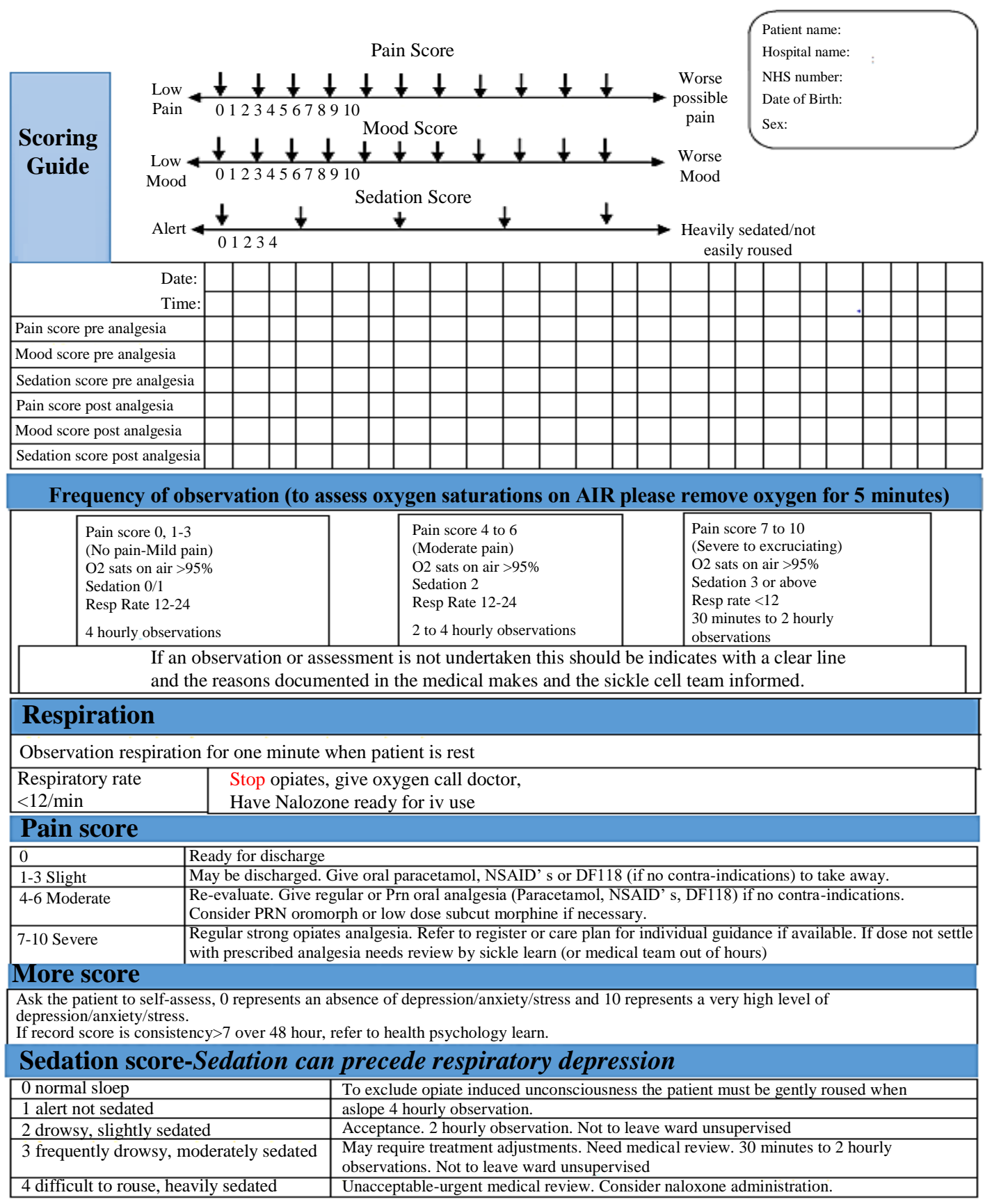

Fig. 4: Pain assessment scale (Howard and Telfer, 2015)

\section{Materials and Methods}

ANN's ability to learn can be used to implement the algorithm capable of learning and optimizing processes involved in the management of pain in SCD patient. Data are collected by hospitals and healthcare centers having records of the entire SCD patients that have been diagnosed and treated. With this data we can determine a patient that has greater risk by processing and analysing the data collected. Neural Network can help to process and analyze patients with sickle cell and those that need immediate attention. The use of ANN can help predict the best practice in management of pain during crisis based on the symptoms. Elsalamony (2016) presented an algorithm to identify healthy and unhealthy sickle cell patient using ANN as structured in Fig. 5. This was a neural network which has input layer, output layer and hidden layer (between input and output layers), but not trained to optimize the processes in the management of pain in SCD. 
Table 4: Related works in neural network based approach to sickle cell disease-related pain management

\begin{tabular}{llll} 
Author & $\begin{array}{l}\text { Methods/ } \\
\text { Techniques }\end{array}$ & Research Focus & Limitation \\
\hline Xu et al. (2017) & $\begin{array}{l}\text { Convolutional } \\
\text { neural network }\end{array}$ & $\begin{array}{l}\text { The paper focused on the modeling of deep } \\
\text { convolutional networks in classification of } \\
\text { different structure of the red blood cell }\end{array}$ & $\begin{array}{l}\text { No focus on pain management of the Sickle } \\
\text { cell diseases-related and the number of datasets } \\
\text { used were small in classifying the SCD. }\end{array}$
\end{tabular}

compared with method of independent structure.

Both methods gave a good prediction and

could assist in the pain of SCD patients.

Hirimutugoda and Artificial Neural

Wijayarathna Network (ANN)

(2010)

McCartney et al. ANN

(2014)

Pombo et al. ICT Technologies

(2014)

Tomari et al.

(2014)

Automated system and ANN

Horn et al.

(2015)

Cella Vision system and ANN

Schneider et al. Optical ANN (2015)

Argüello et al. (2015)

Computational

Coleman et al. model technique

(2016)

Phenomenological Analysis

Tyagi et al.

ANN

(2016)

Durant et al.

Convolutional (2017) Neural Networks

$\begin{array}{ll}\begin{array}{l}\text { Khalaf } \text { et al. } \\ \text { (2017) }\end{array} & \begin{array}{l}\text { Machine learning } \\ \text { Methods/ANN }\end{array} \\ \begin{array}{ll}\text { Rahmat } \text { et al. } & \text { Self-Organizing Map } \\ (2018) & \text { Neural Network. }\end{array}\end{array}$

From Table 4, various researchers acknowledged the fact that there is a demonstrated need for management of pain in SCD. Equally and importantly accepted is the need to optimize the processes of the pain management for better healthcare services.

\section{Training Data for Sickle Cell Disease}

Currently, there is no standardization for pain management in SCD. This paper attempts to develop a neural network model capable of promoting higher-quality care by optimizing the processes in managing sickle cell patients during pain-induced crisis. This will help improve the patient's quality of life with attendant reduction of unnecessary spending, patient illness and pressure for the healthcare practitioners in terms of emergency cases they cell diseases-related and the number of datasets used were small in classifying the SCD.

Unable to manage pain in sickle cell anaemia when a patient is being faced with crisis.

The research did not focus on Sickle cell Diseases in recognizing and optimizing pain.

No techniques to learn and optimize the processes in management of pain.

The automated system was used to train the network in classifying the RBC into normal/abnormal but not for management of pain of the SCD. Few datasets were used to classify using ANN No technique was used to optimize or train network for RBC morphologic abnormalities

ANN was not used to train the network but rather to classify using numerical simulations.

No specific model was used; only suggested a computational model for pain management

No Computational Technique was used in optimizing painful sickling episodes.

Optimizing and prediction of the pain in SCD were not considered.

Morphologic profile of blood cells relies heavily on manual smear processing techniques and visual inspection

No training of datasets. It only provided manual approaches to sickle cell therapy.

System developed could not optimize the process of pain management in SCD 
Table 5: Sickle cell Disease Datasets attributes as enhanced from Khalaf et al. (2016)

\begin{tabular}{|c|c|c|}
\hline $\mathrm{S} / \mathrm{N}$ & Attributes & Meaning \\
\hline 1. & Age & Length of time that the patient has lived \\
\hline 2. & Weight & A body relative mass of that patient \\
\hline 3. & Educational Background & $\begin{array}{l}\text { Highest educational background of the } \\
\text { patient to know the level of literacy }\end{array}$ \\
\hline 4. & Haemoglobin & $\begin{array}{l}\text { The protein found in the Red Blood Cell (RBC) } \\
\text { that carries oxygen to every part of the body. }\end{array}$ \\
\hline 5. & Location & Geographical area and address where the patient lives. \\
\hline 6. & Mean corpuscular volume (MCV) & $\begin{array}{l}\text { The measure of the size of the red blood cells } \\
\text { in the body of the patient. }\end{array}$ \\
\hline 7. & Platelets (PLTS) & $\begin{array}{l}\text { Thrombocytes: refer to components of blood } \\
\text { whose function is to stop bleeding. }\end{array}$ \\
\hline 8. & Neutrophils (WBC NEUT) & Neutrophils helps to fight infections \\
\hline 9. & Neutrophils count (RETIC A) & Real number of White Blood Cells (WBC) present in the patient. \\
\hline 10. & Reticulocyte count (RETIC \%) & $\begin{array}{l}\text { Measures the rate at which reticulocytes are made in the bone } \\
\text { marrow and enter the bloodstream. }\end{array}$ \\
\hline 11. & Alanine Aminotransferase (ALT) test & $\begin{array}{l}\text { The blood test that checks for liver damage. It's an enzyme } \\
\text { mostly in liver and kidney cells }\end{array}$ \\
\hline 12. & Body Bio Blood (BIO) & $\begin{array}{l}\text { BodyBio wellness Report is a revolutionary report that lets you } \\
\text { get the most from the companion blood test. }\end{array}$ \\
\hline 13. & Fetal Hemoglobin (HbF) & The RBC that carries oxygen round the body. \\
\hline 14. & Bilirubin & $\begin{array}{l}\text { Helps to find the cause of health conditions, like jaundice, liver } \\
\text { disease and anaemia. }\end{array}$ \\
\hline 15. & Lactate Dehydrogenase (LDH) & $\begin{array}{l}\text { An enzyme involved in the energy production that is found } \\
\text { in almost the body's entire cell. }\end{array}$ \\
\hline
\end{tabular}

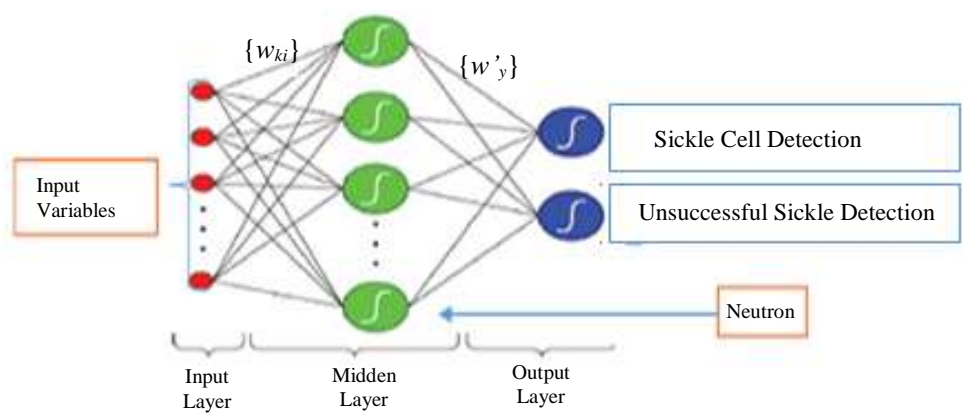

Fig. 5: Multilayer perceptron of the neural network (Elsalamony, 2016)

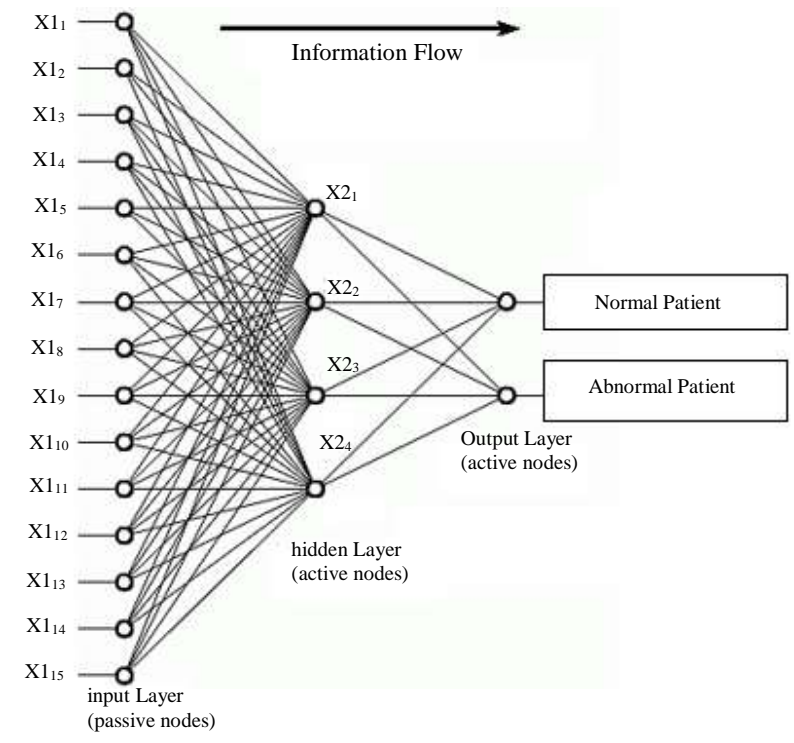

Fig. 6: ANN framework for SCD-Related Pain Management; adapted from Karan et al. (2012) 
Figure 6 presents the neural network to manage the pain in sickle cell patient to be able to determine between normal and abnormal patient in the processes, using the attributes in Table 5.

About 515 datasets were generated using Monte Carlo a Simulation Techniques to Generate Random Number for items in Table 5.

\section{Results}

For the purpose of the work we classified pain into four: low acute pain, severe acute pain, low chronic pain and severe chronic pain (crisis). Our target output percentages are as presented in Table 6 .

Our results using Figs. 6 and 7 are presented in Table 7.

To validate the system, we have a training dataset and testing dataset on classifier model. The evaluation of the neural network was based on some certain parameters such as sensitivity, specificity, precision, the F1 score, Youden's J statistic and the classification accuracy. Table 8 shows the formula to evaluate the performance, where TP, TN, FP and FN stand for true positive, true negative, false positive and false negative respectively for the evaluation performance. Back-propagation method was used for training the datasets. The activation function was determined by the weight of the network, the gradient of the loss function fed into the network to the backpropagation to update the weights of the function in order to reduce the loss function. This was done using a supervised form of learning in ANN. The ANN could learn from the datasets and be able to recommend the best processes in management of pain of sickle disease patient.

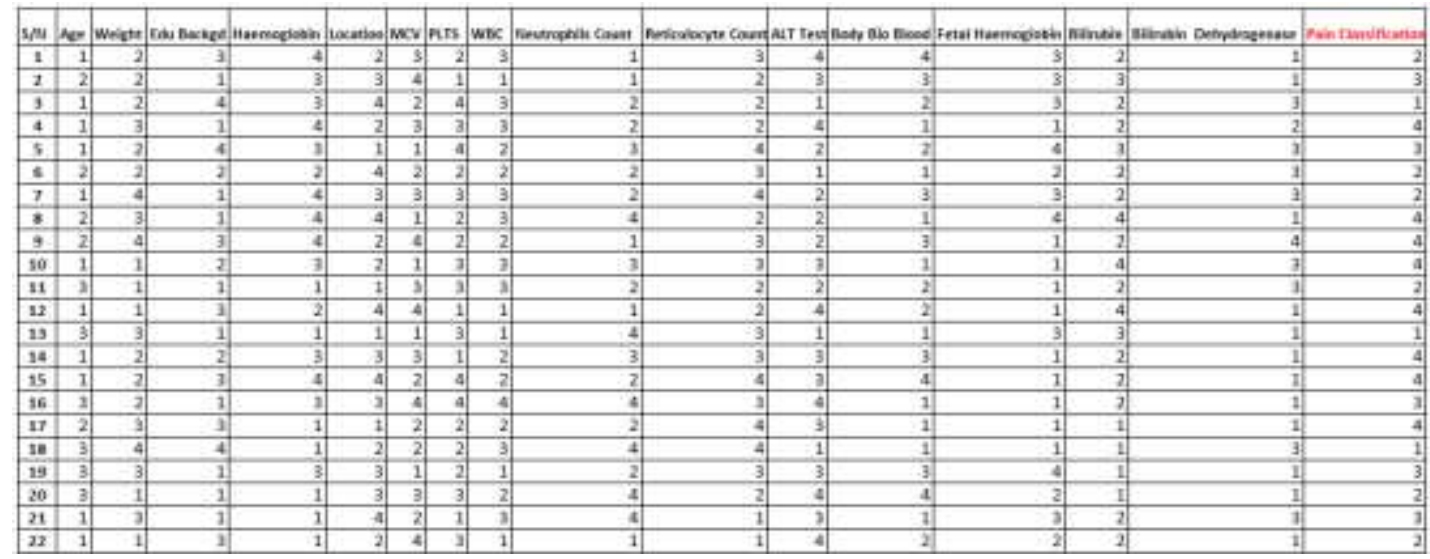

Fig. 7: Sample of data generated

Table 6: Target output percentage

\begin{tabular}{lll}
\hline Pain classification & Percentage classification & Class number \\
\hline Less acute pain & $0-25 \%$ & 1 \\
Severe acute pain & $26-50 \%$ & 2 \\
Less chronic pain & $51-75 \%$ & 3 \\
Severe chronic pain & $76-100 \%$ & 4 \\
\hline
\end{tabular}

Table 7: Attributes classification

\begin{tabular}{|c|c|c|c|c|c|}
\hline $\mathrm{S} / \mathrm{N}$ & $\begin{array}{l}\text { Attributes classification } \\
\text { Class number }\end{array}$ & $\begin{array}{l}0-25 \% \\
1\end{array}$ & $\begin{array}{l}26-50 \% \\
2\end{array}$ & $\begin{array}{l}51-75 \% \\
3\end{array}$ & $\begin{array}{l}76-100 \% \\
4\end{array}$ \\
\hline$\overline{1}$ & Age & $0-25$ years & $26-50$ years & $51-75$ years & 76-100 years \\
\hline 2 & Weight & Under Weight & Normal Weight & Over Weight & Obesity \\
\hline 3 & Educational Background & Illiterate & High School & Graduate & Post Graduate \\
\hline 4 & Haemoglobin & Low & Normal & High & Very High \\
\hline 5 & Location & Rural & Urban & Sub-urban & Exurban \\
\hline 6 & Mean corpuscular Volume(MCV) & Low & Normal & High & Very High \\
\hline 7 & Platelets (PLTS) & Low & Normal & High & Very High \\
\hline 8 & Neutrophils (WBC) & Low & Normal & High & Very High \\
\hline 9 & Neutrophils Count & Low & Normal & High & Very High \\
\hline 10 & Reticulocyte Count & Low & Normal & High & Very High \\
\hline 11 & Alamine Aminotransferase (ALT Test) & Low & Normal & High & Very High \\
\hline 12 & Body Bio Blood & Low & Normal & High & Very High \\
\hline 13 & Fetal Haemoglobin & Low & Normal & High & Very High \\
\hline 14 & Bilirubin & Low & Normal & High & Very High \\
\hline 15 & Bilirubin dehydrogenase & Low & Normal & High & Very High \\
\hline
\end{tabular}


Table 8: Performance metric calculation, adapted from (Karayiannis and Venetsanopoulos, 2013)

\begin{tabular}{ll}
\hline Metric name & Calculation \\
\hline Sensitivity & TP/(TP+FN) \\
Specificity & TN/(TN+FP) \\
Precision & TP/(TP+FP) \\
F1 Score & $2 *($ Precision $*$ Recall $) /($ Precision + Recall $)$ \\
Youden's J statistic (J Score) & Sensitivity + Specificity -1 \\
Accuracy & $(\mathrm{TP}+\mathrm{TN}) /(\mathrm{TP}+\mathrm{FN}+\mathrm{TN}+\mathrm{FP})$ \\
Area under ROC & $0 \Leftarrow$ Area under the \\
Curve (AUC) & ROC curve $\Leftarrow 1$ \\
\hline
\end{tabular}

\section{Discussion}

Back-Propagation Neural Network (Multilayer Perceptron) with supervised learning model has been applied in SCD pain management processes in promoting higher-quality care. The neural network was trained with the SCD patients' datasets features according to the pain encountered in identifying and treating the patient as fast as possible. Performance evaluation metric of the training datasets would help determine the accuracy and effectiveness of the Neural Network for utmost result.

\section{Conclusion}

Inherited disorders of haemoglobin production lead to sickle cell disease. Erythrocyte rigidity and vasoocclusion that are central to the pathophysiology of SCD emanate from haemoglobin polymerization. Chronic anaemia, haemolysis and vasculopathy are important. While clinical management is basic, only few treatments have a robust evidence base. This paper provides a solution to SCD pain management during VOC. Painful episodes can easily be managed by the healthcare sectors to serve as a great relief. The development of this framework would help solve some of the challenges that are faced in the healthcare system in SCD-related pain management.

\section{Acknowledgement}

The authors are indeed grateful to Covenant University for the provision of an enabling working environment. We acknowledge the sustained mentorship by: Professor Charles Onuwa Uwadia (University of Lagos, Lagos, Nigeria), Professor Victor W. Mbarika (Southern University and A\&M College of Business, Baton Rouge, Louisiana, USA) and Professor Sunday O. OJO, Tshwane University of Technology, Pretoria 0001, South Africa).

\section{Funding Information}

No funding was involved in this research work as it forms an extract from the second author's postgraduate degree programme pursuit being supervised by the first author.

\section{Author's Contributions}

Zacchaeus Omogbadegun: Originated and prepared the conceptual framework for the work. He wrote the Abstract, contributed to the Literature Review, edited the work and supervised the work.

Israel Ogundele: Besides contributing to the Literature Review, wrote the initial draft of the work and also used Monte Carlo technique to generate the hypothetical random numbers (test data) for the work based on the expanded attributes.

Olufunke Oladipupo: Reviewed the conceptual framework for the work. Provided cognate materials for the Literature Review, wrote the Conclusion section and co-supervised the work.

Each of the authors read and agreed with the contents.

\section{Ethics}

Monte Carlo Random Number Generation technique has been used in this research to generate dataset using enhanced fifteen attributes. This approach developed a scientific framework that facilitated hypothetical generation of a big dataset without targeting a particular patient or necessarily going through the usual timeconsuming Ethical Approval Committee process of Institutional Review Board. We have also run the manuscript through a plagiarism/similarity check (Turnitin) to ensure the originality and uniqueness of the research work. We have ensured every item in the References List has been properly cited and vice versa. In addition, we have made a direct and substantial contribution to the research.

\section{References}

Afolabi, I.S., I.O. Osikoya and A.M. Okafor, 2016. Phytotherapy and the Relevance of Some Endogenous Antioxidant Enzymes in Management of Sickle Cell Diseases. In: Sickle Cell Disease Pain and Common Chronic Complications, Psalm, B. and D. Inusa (Eds.), IntechOpen, pp: 243-272. 
Agatonovic, K.S. and R. Beresford, 2000. Basic concepts of Artificial Neural Network (ANN) modeling and its application in pharmaceutical research. J. Pharma. Biomed. Anal., 22: 717-727. DOI: 10.1016/S0731-7085(99)00272-1

Akinsete, E. and V. Osu, 2017. The sustainability nexus: Developing resilient communities in emerging nations via clean energy access. ATINER'S Conference Paper Series, Athens.

Akinwonmi, A.E., 2011. On the diagnosis of diabetes mellitus using artificial neural network model. Artificial Neural Netw. Models., 4: 1-8.

Argüello, E.J., R.J. Silva, M.K. Huerta and R.S. Avila, 2015. Computational modeling of peripheral pain: A commentary. Biomed. Eng. Online, 14: 56-56. DOI: $10.1186 / \mathrm{s} 12938-015-0049-\mathrm{X}$

Ballas, S.K., 2005. Pain management of sickle cell disease. Hematology/Oncology Clinic, 19: 785-802. DOI: 10.1016/j.hoc.2005.07.008

Case, M., H. Zhang, J. Mundahl, Y. Datta and S. Nelson et al., 2017. Characterization of functional brain activity and connectivity using EEG and fMRI in patients with sickle cell disease. NeuroImage: Clinical, 14: 1-17.

DOI: 10.1016/j.nicl.2016.12.024

Case, M., S. Shirinpour, H. Zhang, Y.H, Datta and S.C. Nelson et al., 2018. Increased theta band EEG power in sickle cell disease Patients. J. Pain Res., 11: 67-67. DOI: 10.2147/JPR.S145581

Coleman, B., H.E. Caird, J. McGowan and M.J. Benjamin, 2016. How sickle cell disease patients experience, understand and explain their pain: An Interpretative Phenomenological Analysis study. Br. J. Health Psychol., 21: 190-203.

DOI: $10.1111 /$ bjhp. 12157

Creason, C., 2010. Stedman's Medical Terminology: Steps to Success in Medical Language. Lippincott Williams \& Wilkins.

Dampier, C., B. Ely, D. Brodecki, C. Coleman and L. Aertker et al., 2014. Pain characteristics and agerelated pain trajectories in infants and young children with sickle cell disease. Pediatric Blood Cancer, 61: 291-296. DOI: 10.1002/pbc.24796

Dampier, C., T.M. Palermo, D.S. Darbari, K. Hassell and W. Smith et al., 2017. AAPT diagnostic criteria for chronic sickle cell disease pain. J. Pain, 18: 490-498. DOI: 10.1016/j.jpain.2016.12.016

Devi, B.R., K. Rao, S. Setty and M. Rao, 2013. Disaster prediction system using IBM SPSS data mining tool. Int. J. Eng. Trends Technol., 4: 3352-3357.

Durant, T.J., E.M. Olson, W.L. Schulz and R. Torres, 2017. Very deep convolutional neural networks for morphologic classification of erythrocytes. Clin. Chem., 63: 1847-1855.

DOI: $10.1373 /$ clinchem.2017.276345
Edeki, S.O. and O.O. Akanbi, 2017. Simulated data sets for population dynamics of sickle cell anaemia. Data Brief, 16: 876-879. DOI: 10.1016/j.dib.2017.12.006

Elsalamony, H.A., 2016. Healthy and unhealthy red blood cell detection in human blood smears using neural networks. Micron, 83: 32-41. DOI: $10.1016 /$ j.micron.2016.01.008

Ginter, P.M., J. Duncan and L.E. Swayne, 2018. The Strategic Management of Health Care Organizations. 1st Edn., John Wiley and Sons, New Jersey, ISBN-10: 1119349702, pp: 528.

Hirimutugoda, Y.M. and G. Wijayarathna, 2010. Image analysis system for detection of red cell disorders using artificial neural networks. Sri Lanka J. BioMed. Inform, 1: 35-42.

DOI: $10.4038 /$ sljbmi.v1i1.1484

Horn, C.L., A. Mansoor, B. Wood, H. Nelson and D. Higa et al., 2015. Performance of the CellaVision ${ }^{\circledR}$ DM96 system for detecting red blood cell morphologic abnormalities. J. Pathol. Inform., 6: 111. DOI: $10.4103 / 2153-3539.151922$

Howard, J. and P. Telfer, 2015. Treatment of Sickle Cell Disease. In: Sickle Cell Disease in Clinical Practice, Howard, J. and P. Telfer (Eds.), Springer, London, ISBN-10: 978-1-4471-2472-6, pp: 223-260.

Ibrić, S., J. Djuriš, J. Parojčić and Z. Djurić, 2012. Artificial neural networks in evaluation and optimization of modified release solid dosage forms. Pharmaceutics, 4: 531-550.

DOI: $10.3390 /$ pharmaceutics4040531

Jain, A. and C. Gupta, 2016. A genetic algorithm based approach in predicting and optimizing sickle cell Anaemia. Global J. Enterprise Inform. Syst., 8: 9297. DOI: $10.18311 /$ gjeis/2016/15779

Jin, R., W. Chen and A. Sudjianto, 2005. An efficient algorithm for constructing optimal design of computer experiments. J. Stat. Plann. Inference, 134: 268-287. DOI: 10.1016/j.jspi.2004.02.014

Karan, O., C. Bayraktar, H. Gümüşkaya and B. Karlık, 2012. Diagnosing diabetes using neural networks on small mobile devices. Expert Syst. Applic., 39: 54-60. DOI: 10.1016/j.eswa.2011.06.046

Karayiannis, N. and A.N. Venetsanopoulos, 2013. Artificial Neural Networks: Learning Algorithms, Performance Evaluation and Applications. 1st Edn., Springer Science and Business Media, Boston, ISBN-10: 1475745478, pp: 440.

Khalaf, M., A.J. Hussain, D. Al-Jumeily, R. Keight and P. Fergus et al., 2016. Training neural networks as experimental models: Classifying biomedical datasets for sickle cell disease. Proceeding of the 12th International Conference on Intelligent Computing, Aug. 2-5, Springer, Cham, pp: 784-795. DOI: 10.1007/978-3-319-42291-6_78 
Khalaf, M., A.J. Hussain, R. Keight, D. Al-Jumeily and P. Fergus et al., 2017. Machine learning approaches to the application of disease modifying therapy for sickle cell using classification models. Neurocomputing, 228: 154-164. DOI: $10.1016 /$ j.neucom.2016.10.043

Kristiansen, C., 2014. Research needed to treat sickle cell disease in Africa. Global Health Matters Newsletter.

Lanig, I., P. New, A.S. Burns, G. Bilsky and J. BenitoPenalva et al., 2018. Optimizing the management of spasticity in people with spinal cord damage: A clinical care pathway for assessment and treatment decision making from the ability network, an international initiativeve. Arch. Phys. Med. Rehabil., 99: 1681-1687.

DOI: 10.1016/j.apmr.2018.01.017

Lanzkron, S. and H. Carlton, 2015. The five key things you need to know to manage adult patients with sickle cell disease. Hematol. Am. Soc. Hematol. Educ. Program, 2015: 420-5.

DOI: $10.1182 /$ asheducation-2015.1.420

Lanzkron, S., C.P. Carroll and C. Haywood, 2010. The burden of emergency department use for sickle- cell disease: An analysis of the national emergency department sample database. Am. J. Hematol., 85: 797-799. DOI: 10.1002/ajh.21807

Liu, B., M. Wang, H. Yu, L. Yu and Z. Liu, 2006. Study of feature classification methods in BCI based on neural networks. Proceedings of the 27th Annual International Conference on Engineering in Medicine and Biology, Jan. 17-18, IEEE Xplore Press, Shanghai, China, pp: 2932-2935.

DOI: 10.1109/IEMBS.2005.1617088

Macintyre, P.E., D.A. Scott, S.A. Schug, E.J. Visser and S.M. Walker, 2010. Acute Pain Management: Scientific Evidence. 3rd Edn., Australian and New Zealand College of Anaesthetists, Canberra, ISBN-10: 0977517446, pp: 491.

McCartney, S., M. Weltin and K.J. Burchiel, 2014. Use of an artificial neural network for diagnosis of facial pain syndromes: an update. Stereotactic Funct. Neurosurgery, 92: 44-52. DOI: $10.1159 / 000353188$

Piel, F.B., S.I. Hay, S. Gupta, D.J. Weatherall and T.N. Williams, 2013. Global burden of sickle cell Anaemia in children under five, 2010-2050: Modelling based on demographics, excess mortality and interventions. PLoS Med., 10: e1001484e1001484. DOI: 10.1371/journal.pmed.1001484

Poku, A., A.L. Caress and S. Kirk, 2018. Adolescents' experiences of living with sickle cell disease: An integrative narrative review of the literature. Int. J. Nurs. Stud., 80: 20-28.

DOI: 10.1016/j.ijnurstu.2017.12.008
Pombo, N., P. Araújo and J. Viana, 2014. Knowledge discovery in clinical decision support systems for pain management: A systematic review. Artificial Intell. Med., 60: 1-11. DOI: $10.1016 /$ j.artmed.2013.11.005

Rahmat, R.F., F.S. Wulandari, S. Faza, M.A. Muchtar and I. Siregar, 2018. The morphological classification of normal and abnormal red blood cell using self organizing map. IOP Conf. Series: Mater. Sci. Eng., 308: 012015-012015. DOI: 10.1088/1757-899X/308/1/012015

Reader, S.K., N.M. Ruppe, J.A. Deatrick, D.L. Rash Ellis and J.R. Wadman et al., 2017. Caregiver perspectives on family psychosocial risks and resiliencies in pediatric sickle cell disease: Informing the adaptation of the Psychosocial Assessment Tool. Clin. Pract. Pediatric Psychol., 5: 330-341. DOI: 10.1037/cpp0000208

Rees, D.C., T.N. Williams and M.T. Gladwin, 2010. Sickle-cell disease. Lancet, 376: 2018-2031. DOI: 10.1016/S0140-6736(10)61029-X

Schneider, B., G. Vanmeerbeeck, R. Stahl, L. Lagae and P. Bienstman, 2015. Using neural networks for highspeed blood cell classification in a holographicmicroscopy flow-cytometry system. In: Imaging, Manipulation and Analysis of Biomolecules, Cells and Tissues, International Society for Optics and Photonics, San Francisco, California, USA pp: 93281F-93281F.

Siddique, N. and H. Adeli, 2013. Computational Intelligence: Synergies of Fuzzy Logic, Neural Networks and Evolutionary Computing. 1st Edn., John Wiley and Sons, Ltd, United Kingdom, ISBN-10: 9781118337844, pp: 536.

Sun, Y.P., Y. Chen and A.J. Shukla, 2003. Application of artificial neural networks in the design of controlled release drug delivery systems. Adv. Drug Deliv. Rev., 55: 1201-1215. DOI: 10.1016/S0169-409X(03)00119-4

Telfer, P., N. Bahal, A. Lo and J. Challands, 2014. Management of the acute painful crisis in sickle cell disease- a re-evaluation of the use of opioids in adult patients. Brit. J. Haematol., 166: 157-164. DOI: $10.1111 /$ bjh.12879

Tomari, M., M. Razali, W. Zakaria and W. Nurshazwani, 2015. An empirical framework for automatic red blood cell morphology identification and counting. Proceeding of the International Conference on Electrical and Electronic Engineering, Aug. 10-11, Melaka, Malaysia, pp: 10-11.

Tyagi, M., L.M. Saini and N. Dahyia, 2016. Detection of poikilocyte cells in iron deficiency anaemia using artificial neural network. International Conference on Computation of Power, Energy Information and Commuincation, Apr. 20-21, IEEE Xplore Press, Chennai, India, pp: 108-112.

DOI: $10.1109 /$ ICCPEIC.2016.7557233 
US_NIH, 2014. US Department of Human and Health Services -National Institute of Health - National Heart, Lung and Blood Institute; 2014. EvidenceBased Management of Sickle Cell Disease: Expert Panel Report.

Williams, K.H., P.E. Long, J.A. Davis, M.J. Wilkins and A.L. N'Guessan et al., 2011. Acetate availability and its influence on sustainable bioremediation of uraniumcontaminated groundwater. Geomicrobiol. J., 28: 519-539. DOI: 10.1080/01490451.2010.520074
Xu, M., D.P. Papageorgiou, S.Z.M. Abidi, Z.H. Dao and G.E. Karniadakis, 2017. A deep convolutional neural network for classification of red blood cells in sickle cell Anaemia. PLoS Comput. Biol., 13: e1005746-e1005746.

DOI: 10.1371/journal.pcbi.1005746 